\title{
“AMAR A UN HOMBRE FEO": SARMIENTO FICCIONALIZADO - O INSÓLITO DO AMOR NO PARADOXO CIVILIZAÇÃO X BARBÁRIE
}

\author{
“AMAR A UN HOMBRE FEO” [LOVING AN UGLY MAN]: \\ A SARMIENTO'S PORTRAYAL -A SINGULAR LOVE IN THE DICHOTOMY \\ CIVILIZATION VS. BARBARISM
}

\section{Adriana Aparecida Biancato ${ }^{1}$ Gislaine Gomes ${ }^{2}$ Marina Luísa Rohde ${ }^{3}$}

\begin{abstract}
Resumo: Ao optar por uma modalidade híbrida de escrita ficcional e histórica, a escritora argentina Maria Rosa Lojo apresenta em seu conto Amar a un hombre feo (2001) a figura do político e intelectual Domingo Faustino Sarmiento, fragmentada pela visão de sua amada, Ida Wickersham, que o vê como um homem fragilizado em busca do amor. Com base teórica nos estudos pós-coloniais como Santiago (2000), Weinhardt (2002), Fleck (2007;2011), entre outros, o presente artigo explorará o desconstrucionismo do discurso histórico hegemônico através da mediação entre história e ficção mediante o paradoxo civilização x barbárie que confere o aspecto insólito à obra.
\end{abstract}

Palavras-chave: Amores insólitos de nuestra historia (2001); história e ficção; civilização x barbárie; Amar a un hombre feo; literatura latino-americana.

Abstract: Opting for a hybrid modality of fictional and historical writing, the Argentine writer
Maria Rosa Lojo presents in her short story Amar a un hombre feo (2001) the figure of the
politician and intellectual Domingo Faustino Sarmiento, split by the vision of her beloved, Ida

\footnotetext{
1 Possui graduação em LETRAS (Português/Inglês) pela Faculdade de Filosofia Ciências e Letras de Palmas (2003), Especialização em Língua Portuguesa e Literatura pela Faculdade Iguaçu (2006), Especialização em Gestão Escolar pela Universidade Estadual do Centro-Oeste - UNICENTRO (2018) e Mestrado em Letras pela Universidade Estadual do Oeste do Paraná - UNIOESTE (2018). Atualmente é professora da Secretaria de Educação do Estado do Paraná e atua no Núcleo Regional de Educação de Cascavel. Tem experiência na área de Letras, com ênfase em Língua Portuguesa. Integrante do grupo de pesquisa "Ressignificações do passado na América: leitura, escrita e tradução de gêneros híbridos de história e ficção - vias para a descolonização" (http://lattes.cnpq.br/9940727876965128) adri@nrecascavel.com

2 Possui graduação em Letras: Português- Inglês e suas respectivas literaturas, pelo Centro Universitário Assis Gurgacz (2015), pós-graduação em Língua Inglesa (2016) e em Literatura e Ensino (2017), ambas pelo Centro Universitário Assis Gurgacz, e mestrado em Letras -Linguagem e Sociedade pela Universidade Estadual do Oeste do Paraná (2019). Atualmente é professora de língua inglesa - Athus Idiomas. Tem experiência na área de Letras, com ênfase em Línguas Estrangeiras Modernas e Literatura Comparada, atuando principalmente nos seguintes temas: romance histórico contemporâneo de mediação, escrita híbrida de história e ficção, novo romance histórico latino-americano e metaficção historiográfica. Integrante do grupo de pesquisa "Ressignificações do passado na América: leitura, escrita e tradução de gêneros híbridos de história e ficção vias para a descolonização" (http://lattes.cnpq.br/2528918872272386) gislainegomes24@ hotmail.com

${ }^{3}$ Mestre em Letras (Estudos Comparados e Literatura) pela Universidade Estadual do Paraná (2018). Possui graduação em Letras - Português/Inglês pela Universidade Estadual do Oeste do Paraná, campus de Cascavel (2014). Integrante do grupo de pesquisa "Ressignificações do passado na América: leitura, escrita e tradução de gêneros híbridos de história e ficção - vias para a descolonização". Atua como professora de inglês. (http://lattes.cnpq.br/3222275052685746) marinaluisar@gmail.com
} 
Wickersham, who sees him as a fragile man searching for love. Based on postcolonial studies such as Santiago (2000), Weinhardt (2002), Fleck (2007; 2011), among others, this paper will explore the deconstructionism of hegemonic historical discourse through the mediation between history and fiction through the civilization $\mathrm{x}$ barbarism paradox that gives the unusual aspect to the work.

Keywords: Astonishing love affairs in Argentine History [Amores insólitos de nuestra historia, 2001]; history and fiction; civilization vs. barbarism; Amar a um hombre feo [Loving an ugly man]; Latin American literature.

\section{Introdução}

A obra Amores Insólitos de Nuestra Historia (2001), da escritora argentina María Rosa Lojo, simboliza a hibridização da história, ficção e memória frequente nas produções narrativas contemporâneas do gênero romance histórico. O livro publicado em 2001 é composto de catorze contos que, por meio da literatura, retrata a ocupação da Argentina no século XIX.

Neste texto temos como objetivo analisar o conto "Amar a un hombre feo", um dos relatos que compõe a obra acima citada, no qual o paradoxo civilização x barbárie é o que confere à história o aspecto insólito. O conto apresenta a personagem de extração histórica, Domingo Faustino Sarmiento, um dos políticos e intelectual mais importantes do século XIX da Argentina. No relato ficcional sua figura é fragmentada pela visão da amada, a personagem Ida Wickersham - também de extração histórica -, que o vê como um homem fragilizado em busca do amor.

María Rosa Lojo, ao dedicar-se a reler a história do passado argentino - entrelaçado com as memórias remanescentes da Galícia espanhola de onde vieram seus pais - opta por uma modalidade de escrita ficcional híbrida, seja nos contos ou nos romances, cuja linguagem se aproxima bastante do cotidiano do falante hispânico contemporâneo. As narrativas são, geralmente, lineares e, embora se apresentem releituras críticas do passado, a autora opta por estratégias escriturais menos desconstrucionistas do que aquelas que caracterizam o novo romance histórico latino-americano (paródia, carnavalização, ironia, grotesco).

Sua leitura do passado empreende muito mais uma "humanização" das grandes figuras históricas - como veremos no conto selecionado - do que a própria desconstrução das imagens consagradas destes pelo uso dos recursos escriturais empregados pelo gênero acima referido. Diante dessa realidade, podemos afirmar que María Rosa Lojo é uma representante 
exemplar da escrita híbrida que Fleck (2017) classifica como "mediadora" entre o tradicionalismo e o criticismo/desconstrucionismo latino-americano. Uma obra composta da hibridação entre memória, história e ficção, na qual os textos nela expostos transpassam a hegemonia do discurso oficial em memórias coletivas e individuais.

Com relação à estrutura, os contos da obra em destaque seguem uma trajetória temporal - começam no período da conquista (1577), revisitam a história hegemônica rio-platense e alcançam a modernidade (1913). Este repertório permitirá à escritora a tão desejada (re)territorialização do espaço imaginário e o arraigamento identitário, constituindo assim, um sentimento de pertença a uma territorialidade geográfica e simbólica. Ao propormos a análise do aspecto insólito presente na narrativa selecionada, buscamos a reflexão que a própria autora traz no prólogo do livro sobre temas como o amor e o poder, testemunhos dos paradoxos que sempre estiveram presentes na literatura.

A redundância dos amores com o insólito que o acompanha é explorado pelos personagens Sarmiento e Ida por meio da civilização almejada pelo primeiro e a barbárie que lhe é própria, responsável pelo encantamento da amada. Como base teórica deste estudo serão utilizados, entre outros, os pressupostos dos estudos pós-coloniais, bem como aqueles expressos por Santiago (2000), Weinhardt (2002), Fleck (2007; 2011; 2017), a fim de explorar a configuração do insólito na hibridização das personagens de extração histórica.

\section{História e Ficção na produção contista de María Rosa Lojo}

A escrita híbrida de história e ficou consagrou-se no gênero romanesco no século XIX. O romance histórico, segundo Fleck (2007), é caracterizado como uma narrativa híbrida entre elementos da ficção e os eventos históricos que são relidos de acordo com a ideologia que move as diferentes modalidades do gênero. Essa escritura híbrida tem a possibilidade de recriar o comportamento humano e, em algumas de suas modalidades, dar voz a outros discursos, além do oficial. García Gual (2002) destaca que o caráter híbrido desse gênero alavanca novos olhares, daquilo que não se mostrou, que despertam maior envolvimento do leitor, que se aventura nesse nuance do romance histórico.

Entre as modalidades do gênero, destacamos, romance histórico clássico (LUKÁCS, 2000); romance histórico tradicional (MÁRQUEZ RODRÍGUEZ, 1996; FLECK, 2017); novo romance histórico latino-americano (AÍNSA, 1991; MENTON (1993); metaficções historiográficas (HUTCHEON, 1991) e romance histórico contemporâneo de mediação 
(FLECK, 2007-;2017). Com exceção da clássica, todas as demais modalidades seguem sendo produzidas ao redor do mundo.

Esse é o cenário da narrativa híbrida latino-americana, uma vez que as rupturas sofridas pelo romance histórico, desde seu surgimento, com Walter Scott, em 1814, acentuaram-se em nosso meio e deram origem a uma forma diferenciada de romance histórico - o novo romance histórico latino-americano - a qual já convive com outras modalidades críticas do gênero como a metaficção historiográfica e o romance histórico contemporâneo de mediação de mediação, classificado e descrito por Fleck (2017).

Essas produções são peculiares em solo latino-americano, pois, de acordo com Fleck (2007), a história aqui registrada foi contada pelos colonizadores europeus, mas não durou por muito tempo para essas versões serem desconstruídas pelos nossos literatos. Desse modo, o pesquisador comenta: "a literatura latino-americana ao longo dos séculos vem tentando se libertar do jugo dos países dominantes. Ela segue buscando na contemporaneidade [...] seus modos próprios de expressão.” (FLECK, 2007, p.162-163).

De acordo com Santiago (2000), o propósito maior do europeu que chegou ao "Novo Mundo" foi combater o bilinguismo e a aceitação de outra manifestação religiosa. A eles interessava apenas uma verdade: "Um só Deus, um só Rei, uma só Língua” (SANTIAGO, 2000, p. 14). Daí a intenção de que a origem das Américas fosse simplesmente apagada pelos conquistadores. No entanto, o escritor latino-americano resiste. Na sua situação de assimilador do 'modelo', ainda nas palavras de Santiago (2000), produz um novo texto que tem a função de afrontar e/ou negar o primeiro.

María Rosa Lojo está entre os escritores que, por meio de suas manifestações literárias, traduzem o que Santiago chamou de "entre-lugar" da literatura latino-americana. Este é seu lócus enunciativo, conforme definiu Silviano Santiago (2000) o espaço no qual se manifestam os escritores latino-americanos contemporâneos, que buscam transpor os conflitos entre colonizador e colonizado.

Herdeira do exílio de seus pais, María Rosa, por meio do processo criativo, deseja fundar uma territorialidade, apropriando-se dos espaços simbólicos que a rodeiam para (re) territorializar-se no espaço cultural, político e linguístico argentino, por meio da expressão estética memorialista. Suas obras ressemantizam a história das Américas, projetam um novo olhar sobre as personagens femininas representativas da história, mas, sobretudo, concedem um lugar de enunciação às amantes, às criadas, às indígenas, às mestiças, às cativas. 
De acordo com Papeschi (2014), grande parte das narrativas híbridas de Lojo insere-se no momento histórico do século XIX na Argentina, justamente no período em que surgem conflitos quanto à nacionalidade e à independência do país, caracterizada pela dicotomia civilização x barbárie, aspecto esse explorado no conto selecionado, cuja análise segue.

\section{A obra - Amores insólitos de nuestra historia - 2001}

Essa é uma obra composta da hibridação entre memória, história e ficção configurada na escrita de contos. Os textos nela expostos transpassam a hegemonia do discurso oficial em memórias coletivas e individuais. Os contos estão organizados em uma trajetória temporal que começa no período da conquista do território americano (1577), revisita a história hegemônica rio-platense do período da fundação da nação e alcançam a modernidade (1913).

Essa linha temporal cronológica permitirá à escritora embarcar no projeto da (re)territorialização do espaço ocupado pelo discurso eurocêntrico, com perspectivas diferenciadas daquelas consagradas na história e o arraigamento identitário de um povo híbrido e mestiço, constituindo, assim, um sentimento de pertença entre a grande multiplicidade cultural reinante nessa territorialidade geográfica e simbólica.

Conforme prólogo do livro, María Rosa considera que o amor e o poder sempre estiveram presentes na literatura, testemunhos dos paradoxos, "[...] éxtasis y desdicha, violencia y paz, fugacidade y permanencia, el amor aparece como la eterna contradicción y, a la vez, como la instancia superadora de las antinomias." (LOJO, 2001, p. 14).

Nesse sentido, Amores Insólitos seria uma redundância, uma vez que todos os amores são insólitos? Esta questão é elaborada e respondida pela própria autora no prólogo do livro, bem como em uma entrevista cedida à Revista de Arte, Cultura e Psicanálise:

La propuesta del libro habla de aquellos amores que llevan al extremo la tensión entre los elementos diferentes puestos en contacto por la pasión amorosa. No para anular las diferencias, que son ricas y está bien que existan, sino para superarlas en una alianza novedosa que las trasciende. Los amores insólitos funcionan, por eso, como las metáforas vanguardistas con sus combinaciones sorprendentes. Sus cuentos no narran historias "felices", sino más bien historias arriesgadas, de apuestas que parecen imposibles, historias de cruces y asimetrías de todo tipo: de etnia, de clase social, de poder, de religión, de todo lo que uno se pueda imaginar, y que no impiden que la pasión se desencadene, cualquiera sea el resultado. Por el contrario, más bien la fomentan. Ahí se aplica lo de la alquimia, con su búsqueda de la totalidad, de la completud (GUIROY, 2014). 
Essa temática acompanha a escritora em muitas de suas produções ficcionais, assim como o cultivo da memória, o uso da escrita para "selecionar" aquelas lembranças que persistem ao tempo, buscando a sua "materialização". A produção escrita de María Rosa Lojo circula entre ficção, História e memória que percorrem as trilhas dos elementos históricos da ocupação argentina no século XIX. O tema que se fixa, constantemente, em suas produções literárias é representado pela reflexão acerca da identidade do argentino, marcada pelas mesclas étnicas e culturais. As relações entre a civilização europeia e a barbárie local, tantas vezes mencionado na origem nacional argentina, erigem o discurso literário de Lojo que, de acordo com Esteves (2016), representa um rompimento de fronteiras.

Para Crespo (2008), María Rosa Lojo, em seu local de entrecruzamentos de histórias, nas suas contradições, explora estas questões nas suas produções literárias que tratam da problemática da elucidação da verdade histórica. Crespo (2008) destaca ainda que os textos desta autora circulam no sistema literário argentino das últimas décadas, atravessados por uma série de questões, tais como: a problemática da pós-modernidade, a reformulação da história argentina e americana, a elaboração da estética da violência coletiva e do exílio, a ruptura da imagem feminina tradicional.

Suas ficções, como a de outros escritores que transitam no gênero, têm seu modelo formal e pragmático no relato historiográfico - ainda que se orientem em distintos propósitos -, mas também nas tradições populares e na narrativa histórica que lhe precede. Em seus relatos ficcionais, María Rosa inscreve novas versões dos fatos, de acordo com seus próprios modelos culturais.

Nas narrativas híbridas de Lojo, as personagens históricas são ficcionalizadas e tal processo lhes assegura a humanização necessária que lhes permite a possibilidade de contar uma "outra" história, sob uma perspectiva diferente daquela exposta na historiografia hegemônica oficial. Nesse processo escritural, María Rosa faz sua opção por essa via da "humanização" dos grandes heróis nacionais e pela "evidenciação de vozes silenciadas" com relação àquelas personagens marginalizadas nos discursos oficiais.

Este é o contexto em que se situa a obra Amores Insólitos de nuestra historia (2001), composta por relatos que contam os amores incomuns de personagens que transgrediram a ordem 'natural' das convenções sociais, personagens essas que habitam os livros de História da Argentina ou que foram ignoradas pela historiografia. 
Munida da possibilidade que o discurso literário lhe concede de revisitar o passado e contestar a perspectiva única dos fatos registrados pela história oficializada, a autora oferece ao leitor um novo olhar à Argentina do século XIX e reconstrói personagens históricas, reposicionando-as dentro de uma hierarquia que parecia inabalável. Para tal, a autora emprega a liberdade que a Literatura lhe oferece, conforme afirma Fleck (2013), concedendo, assim, ao leitor, revisitar a História, reinterpretá-la, reescrevê-la.

Os relatos da obra selecionada contam insólitas histórias de amor que se passaram com personagens que circulam pelos livros de História da Argentina renarrativizadas pelo viés das relações entre História e Literatura. O conto escolhido, cuja abordagem fazemos à continuação, é um bom exemplo disso.

\section{0 conto - "Amar a un hombre feo"- (LOJO, 2001)}

Consoante à organização linear feita pela autora, o conto "Amar a un hombre feo "4 é o nono dos relatos que compõe a obra Amores Insólitos de nuestra história (2001). Em sua composição, é a dicotomia da civilização x barbárie que confere à História o aspecto insólito que amalgama todas as narrativas reunidas na coletânea.

O conto narra a história de amor ente Domingo Faustino Sarmiento (1811-1888), político e intelectual argentino, e Ida Wickersham (1841-1891), jovem norte americana, casada com um médico, o Dr. Wickersham.

Sarmiento conhece Ida em Chicago durante uma viagem que fez aos Estados Unidos para conhecer o sistema educacional daquele país que tanto admira, apresentados pelo próprio cunhado de Ida, o professor James Wickersham, os dois passam a se encontrar com frequência com a desculpa de Sarmiento ter aulas de inglês com a bela jovem. No entanto, o intelectual, envolvido com as atividades no âmbito político, logo se distancia de Ida, que passa a se corresponder com o amado por meio de cartas.

A relação entre ambos passa a ser apenas epistolar quando Sarmiento retorna à Argentina para assumir a presidência da república. Ida, uma mulher bela e que amou um homem desprovido de beleza, foi abandonada por ele e pelo marido, que descobriu sua traição pelas cartas encontradas, acaba sozinha, pobre, envelhecida. A última parte relata o fim de Ida, a sua morte, pela voz narrativa de seu marido, que é comparado a Sarmiento, o primeiro apresentado como uma pessoa fechada, mergulhado nos seus próprios conflitos, enquanto que

\footnotetext{
${ }^{4}$ Nossa tradução: Amar a um homem feio.
} 
o amante de sua esposa é descrito como alguém que domina a palavra e utiliza este recurso como instrumento de conquista.

Tanto o título - "Amar a um hombre feo" - como a epígrafe - que María Rosa Lojo utiliza são fragmentos de um diário de Sarmiento ${ }^{5}$ de quando esteve nos Estados Unidos, nas partes que compõe uma dedicatória a Aurelia Vélez.

“... desde mis primeiros passos en la vida sentí casi siempre a mi lado una mujer, atraída por no sé qué misterio [...]. Debe haber en mis miradas algo de profundamente dolorido que excita la maternal solicitud feminil [...] ¿Por qué una beldad ama a un hombre feo?" DOMINGO F. SARMIENTO, UN VIAJE DE NUEVA YORK A BUENOS AIRES... ${ }^{6}$ (LOJO, 2001, p. 193).

Nessa dedicatória, o diplomata argentino se pergunta como ele, que sempre esteve permeado por figuras femininas e desprovido de beleza, foi alvo da paixão de uma bela mulher.

O conto está dividido em quatro partes: a primeira delas se intitula " "El hombre feo1865-1867' e narra o encontro amoroso entre Ida e Sarmiento, desde a perspectiva do político/escritor argentino, como se observa em:

La cabeza y los ombros de la bella emergen entre encajes. [...] la beldad nos es discreta, [...] toda ella desborda, como un exceso fulgurante, sobre el coro mesurado de las demás espectadoras. [...] ¿A qué medios podría recurrir para ser presentado a esa encarnación mortal de la Belleza $?^{7}$ (LOJO, 2001, p. 193-194).

Quem nos apresenta as personagens é um narrador onisciente e o relato da cena do primeiro encontro entre os protagonistas é realizado por meio da descrição de Ida, na visão de Sarmiento, em um teatro, como uma beldade, como se pode observar no excerto acima

\footnotetext{
${ }^{5}$ Un viaje de Nueva York a Buenos Aires - de 23 de julio al 29 de agosto de 1868 - relato da viagem realizada por Domingo Faustino Sarmiento aos Estados Unidos, publicado pela primeira vez em 1900 e editado por Augusto Belín Sarmiento, neto do autor, que compilou as Obras Completas de Faustino Sarmiento em 52 tomos, declarou em Nota Introdutória que o texto tem sua gênese de "un cuadernillo manuscrito", o qual relata as viagens que Sarmiento empreendeu aos Estados Unidos, a fim de conhecer o sistema educacional do país, nas páginas 8 e 257 do diário registra a sua dedicatória a Aurelia Vélez.

${ }^{6}$ Nossa tradução: ... desde meus primeiros passos na vida quase sempre senti uma mulher ao meu lado, atraída por não sei que mistério [...]. Deve haver nos meus olhos algo profundamente doloroso que excita o instinto feminino materno [...] Por que uma beldade ama um homem feio? "Domingo S. SARMIENTO, UMA VIAGEM DE NOVA YORK PARA BUENOS AIRES".

${ }^{7}$ Nossa tradução: A cabeça e os ombros da bela emergem entre laços. [...] a beleza não é discreta, [...] toda ela transborda, como um excesso brilhante, sobre o coro medido das demais espectadoras. [...] A que meios ele poderia recorrer para ser apresentado àquela encarnação mortal da Beleza?
} 
mencionado. Assim, os dois se conhecem e ela se oferece para ajudá-lo com aulas particulares de inglês, fato esse que os aproxima, facilitando o romance.

Nesses encontros, Sarmiento se vê particularmente despido de sua identidade ao entregar-se à amada e a uma nova territorialidade, tanto física, como simbólica, conforme relata o narrador:

Ella le sonríe, y la tierra extranjera se vuelve para él un lugar cómodo, cercano y habitable. Hasta el inglés, en el que tanto le cuesta entenderse con otros varones, le parece una música íntima que sus propios labios podrían modular sin inconvenientes. $^{8}$ (LOJO, 2001, p. 194).

Dessa maneira, Sarmiento se apropria dessa nova territorialidade, por meio da posse do corpo e do afeto de Ida e, simbolicamente, pela aceitação da barbárie latente, que havia por ele, sido inviabilizada.

Na segunda parte - "Las Cartas - 1867-1868", o leitor tem acesso aos apelos epistolares de Ida, rememorando os momentos vividos e buscando manter o relacionamento, é o que se evidencia em: "Ninguna carta de usted desde el sábado! Me siento decepcionada. Esperaba una más antes de salir para el oeste; [...] Creo que si usted hubiera estado aquí le habría emitido algunos rayos solares. ${ }^{9}$ " (LOJO, 2001, p. 201).

Neste momento, Sarmiento já separado de Ida, pois agora está em Nova Iorque, corresponde-se com ela por cartas. O que se percebe é a súplica de Ida para que o amado a responda, é o que se evidencia em: “'Sarmiento mío! Escríbame pronto a Chicago, que sean largas cartas. Yo las corregiré. Éste es mi adiós desde el oeste. Un beso. Suya. Ida. ${ }^{10 ",}$ (LOJO, 2001, p. 201).

No entanto, Domingo Faustino já está mais envolvido com a política e parece não corresponder a este amor como Ida ainda o faz. Ela relata em suas cartas sobre sua vida e o desencanto com que convive, de acordo com o que se observa em:

Si usted ha recibido cualquiera de mis cartas, sabrá que me divorcie del doctor... y que he estado viviendo en Nueva York los últimos años y medio. Han sido para mí

\footnotetext{
${ }^{8}$ Nossa tradução: Ela lhe sorri e a terra estrangeira torna-se um lugar confortável, próximo e habitável para ele. Até o inglês, que tanto lhe custa para entender-se com outros homens, parece uma música íntima que seus próprios lábios poderiam modular sem inconvenientes.

${ }_{9}^{9}$ Nossa tradução: Nenhuma carta sua desde sábado! Me sinto decepcionada. Esperava mais uma antes de partir para o oeste; [...] creio que se você estivesse aqui teria emitido alguns raios solares.

${ }^{10}$ Nossa tradução: Sarmiento meu! Escreve-me em breve a Chicago, que sejam longas cartas. Eu as corrigirei. Este é meu adeus até o oeste. Um beijo. Sua Ida.
} 
años de arduo estudio y muchos contratiempos, puesto que quise aprender un oficio con el cual ganarme la vida, pero hasta ahora no he tenido éxito. [...] es un trabajo duro para una mujer, especialmente para quien no ha sido educada para eso. ${ }^{11}$ (LOJO, 2001, p. 209).

A terceira parte, que traz como título - "La Beldad - Nueva York, 1882”, relata o destino de Ida, a bela mulher que amou um homem inteligente e desprovido de beleza. $\mathrm{O}$ narrador conta a trajetória da beldade, seu divórcio, a luta por realizar um ofício, uma vez que sempre teve uma vida tranquila em relação ao dinheiro, a adoção de seu nome de solteira Ida Lacey - e o amor que ainda mantém por Sarmiento, como se pode observar nos excertos anteriormente mencionados.

Este momento da narrativa arremessa-nos temporalmente ao futuro e nos deparamos com Ida, evocando e revisando seu passado.

\begin{abstract}
Como quien examina, fríamente, los resultados ya irremediables de un mal negocio, Miss Lacey, que con los años, se ha vuelto calculadora, traza con pulso profesional en medio de la hoja vacía, una línea que divide el debe y el haber. Ha perdido: [...] Un amante latino (feo, corpulento, más que maduro, pero también inteligente [...] Las cómodas habitaciones amuebladas de Hotel St. James, y casi todas sus pertenencias [...] Un marido [...] El dinero que le correspondió después de la separación. ${ }^{12}$ (LOJO, 2001, p. 207).
\end{abstract}

A última parte, "El doctor Wickersham - Chicago, 1891", é apresentada sob o foco narrativo do ex-marido, o qual relata a morte de Ida e recorda como descobriu a traição da esposa por meio das cartas dela e seu amante, que ele encontrou sem desejar, como se constata em:

Medita sobre el extraño poder de las causalidades. Sí la mayoría de sus pacientes
no hubieran faltado inexplicablemente una tarde de 1874 , él no habría vuelto al
Hotel Matteson. Si Ida no hubiese estado fuera, ocupada en sus clases de francés
[...] El doctor Wickersham leyó todas las cartas [...] frases de amor [...]. ${ }^{13}$ (LOJO,
2001, p. 212-213).

${ }^{11}$ Nossa tradução: Se você recebeu alguma das minhas cartas, saberá que me divorciei do doutor e que estou vivendo em Nova York nos últimos anos. Tem sido para mim anos de árduo estudo e muitos contratempos, posto que quis aprender um ofício com o qual ganharei a vida, mas até agora eu não tenho tido sucesso. [...] é um trabalho duro para uma mulher, especialmente para aquelas que não foram educadas para isso.

${ }^{12}$ Nossa tradução: Como alguém que examina, friamente, os já irremediáveis resultados de um mau negócio, Miss Lacey, que ao longo dos anos tornou-se calculista, traça com pulso profissional no meio da folha vazia, uma linha que divide o débito e o crédito. Ela perdeu: [...] Um amante latino (feio, corpulento, mais que maduro, mas também inteligente [...]. Os confortáveis quartos mobiliados do Hotel St. James, e quase todos os seus pertences [...], um marido [...], o dinheiro que lhe correspondia depois da separação.

${ }^{13}$ Nossa tradução: Medita sobre o estranho poder da causalidade. Se a maioria de seus pacientes não tivesse faltado inexplicavelmente em uma tarde de 1874, ele não teria retornado ao Hotel Matteson. Se Ida não estivesse ausente, ocupada em suas aulas de francês, [...] o Dr. Wickersham leu todas as letras [...] frases de amor [...]. 
Como é um homem fechado, o que o difere de Sarmiento, dono de uma exímia arguição, resolve sair de casa, sem explicações, revelado ao leitor em: "Swayne Wickersham no pudo llorar, ni siquiera gritar o destruir. [...] Nunca volvió del consultorio ni Ida Lacey le pidió que volviese. ${ }^{14 "}$ (LOJO, 2001, p. 213).

O desenlace do conto é apresentado sob o viés do jovem doutor com quem Ida foi casada, descrito na voz do narrador, como se observa no fragmento:

El doctor Swayne Wickersham ha decidido cerrar temprano el consultorio. No todos los días muere una ex esposa (después de todo la única esposa que ha tenido). [...] Abre uno de los cajones de su cómoda. Desenvuelve un retrato guardado entre pañuelos. Ida a los treinta y tres años, la misma época en que él abandonó las habitaciones compartidas en el Matteson Hotel para trasladarse a su consultorio. [...] Ya no podrá recordarla sino de esta manera. ${ }^{15}$ (LOJO, 2001, p. 210 e 211).

O conjunto das quatro partes engloba, temporalmente, os princípios do idílio amoroso, o rompimento da relação, o processo de autoconscientização de Ida (enquanto mulher e sujeito) e sua morte - sob a perspectiva do ex-marido.

A relação amorosa evidencia a hibridez das identidades das personagens, descrita pela situação de um homem político/civilizado/literato argentino, caracterizado como feio, apaixonar-se por uma bela norte-americana, que tem como únicas atividades a ópera, os passeios e as compras.

Nesse enlace amoroso, Sarmiento sofre uma ruptura com sua identidade tradicional, em um dos encontros dos amantes às margens do Brandywine, percebe-se o lapso desmemorial por que passa o protagonista, pois, enquanto Ida se desvencilha de suas roupas, o leitor centra-se em Sarmiento, que utiliza estratégias para movimentar-se na nova territorialidade física e simbólica que se apresenta.

Dessa maneira, a personagem envolve-se nas tramas do esquecimento e da imaginação, a fim de se desprender do que o levou a ser um homem das letras e das armas:

\footnotetext{
${ }^{14}$ Nossa tradução: Swayne Wickersham não pode chorar, nem mesmo gritar ou destruir. [...] Nunca voltou do escritório ou Ida Lacey pediu para ele voltar.

15 Nossa tradução: Dr. Swayne Wickersham decidiu fechar o escritório mais cedo. Não são todos os dias que morre uma ex-esposa (depois de tudo a única esposa que ela já teve). [...] Abre uma das gavetas da sua cômoda. Desempacota um retrato guardado entre lenços. Ida aos trinta e três anos, a mesma época em que deixava os quartos compartilhados do Matteson Hotel para se mudar para seu escritório. [...]. Já não poderá lembrar-se dela, exceto desta maneira.
} 
"La absolución del agua parece ir borrando nombres, caras, fechas, amores, y sobre todo

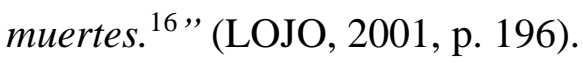

Sarmiento, por sucumbir ao desejo de possuir Ida, precisará enfrentar um abismo que lhe fará perder os referenciais simbólicos, linguísticos e identitários. Assim, conforme Coelho (2015), será exposto a uma nova territorialidade simbólica e, seduzido, passa a relativizar estes construtos identitários que ele - enquanto indivíduo localizado historicamente reivindicou, assumindo, desse modo, a barbárie para conquistar Ida.

O conto "Amar a un hombre feo" apresenta, pois, a personagem de extração histórica, Domingo Faustino Sarmiento, um dos políticos e intelectual mais importantes do século XIX da Argentina. No relato ficcional sua figura é fragmentada pela visão da amada, a personagem Ida Wickersham - também de extração histórica -, que o vê como um homem fragilizado em busca do amor.

Nesse sentido, a redundância dos amores com o insólito que o acompanha é explorada nessa releitura do passado pelo conto histórico por meio das aventuras vividas pelas personagens Sarmiento e Ida e se concretiza por meio da civilização almejada pelo primeiro e a barbárie que lhe é própria, responsável pelo encantamento da amada que, na perspectiva conservadora, ao ser cidadã estadunidense, representa a civilização pretendida pelo latinoamericano.

De acordo com Papeschi (2014), grande parte das narrativas híbridas de Lojo insere-se no momento histórico do século XIX da Argentina, justamente no período em que surgem conflitos quanto à nacionalidade e à independência do país, caracterizada por essa dicotomia civilização x barbárie, aspecto esse explorado no conto "Amar a un hombre feo".

Nesse relato, o protagonista, Domingo Faustino Sarmiento, que tanto deseja o progresso e a civilização para sua terra e para si mesmo, é visto pela amada, a personagem Ida Wickersham - representante da metrópole americana - como um selvagem. Contudo, é justamente esse elemento constituinte do ser de Sarmiento que lhe encanta, que lhe atrai e faz com que ela se apaixone por ele. Na verdade Ida despreza as "prestigiosas filiaciones ${ }^{17}$ ”, pois "en realidad, Ida Wickersham, que se jacta de su pelo azabache y de su apelido paterno

\footnotetext{
${ }^{16}$ Nossa tradução: A absorção da água parece que está apagando nomes, rostos, datas, amores e especialmente mortes.

${ }^{17}$ Nossa tradução: prestigiosas filiações.
} 
francés, estima en bastante poco estas dos últimas [...] lo anglosajón y lo protestante. ${ }^{18 \text { " }}$ (LOJO, 2001, p. 199).

A bela jovem norte americana aprecia a barbárie abdicada por Sarmiento, como se destaca em:

A veces, en las noches pacíficas junto al Brandywine, la señora Wickersham cree abrir los ojos entre la maraña de un bosque desconocido. En un claro de ese bosque un varón de torso veludo acaba de dominar a un tigre sólo con la mirada intimidatoria y la fuerza insospechada de las manos [...] Ida no ve los gatos grandes [...] Ve un tigre de Bengala cuyo matador se parece más a un jeque árabe o a un pirata malayo con un kriss, que a un hacendado de Los Llanos con él facón al cinto. ${ }^{19}$ (LOJO, 2001, p. 200).

Segundo analisa Papeschi (2014), como ocorre com a personagem Ida, o leitor, ao acompanhar o enredo do conto, também é levado a perceber Sarmiento civilizado por meio da imagem de um bárbaro, devido às atitudes da personagem no texto, que se observa por meio do narrador onisciente enquanto descreve os pensamentos da personagem às margens do Brandywine:

[...] La muerte anterior de su enemigo, el general montonero Ángel Peñaloza, llamado "el Chaco", cometida de acuerdo con los más clásicos cánones del Caos o de la Barbarie que ahora vuelve acusadora, como un bumerán, desde la mano manchada de sus propios hombres. ${ }^{20}$ (LOJO, 2001, p. 196).

Quanto à gênese deste conto, o leitor fica sabendo, por meio da bibliografia da obra, bem como pelo posfácio, que Lojo utilizou como leitura base para essa renarrativização o livro do professor Enrique Anderson Imbert, Uma aventura amorosa de Sarmiento: cartas a Ida Wickersham, volume publicado, de acordo com Esteves (2011), após uma pesquisa do referido professor argentino na busca de matérias para sua obra Genio y figura de Sarmiento (1967).

\footnotetext{
${ }^{18}$ Nossa tradução: De fato, Ida Wickersham, que se orgulha de seu cabelo preto e seu nome paterno francês, estima em muito pouco [...] estes dois últimos, o anglo-saxão e o protestante.

${ }^{19}$ Nossa transdução: Às vezes, nas noites tranquilas ao lado do Brandywine, a Sra. Wickersham acredita abrir os olhos entre o emaranhado de uma floresta desconhecida. Em uma clareira naquela floresta, um macho de peludo torso acaba de dominar um tigre com apenas o olhar intimidador e força insuspeita das mãos [...] Ida não vê grandes felinos [...] Vê um tigre de Bengala cujo matador se parece mais com um xeique árabe ou um pirata malaio com um kriss do que um proprietário de terras de Los Llanos com seu facão em seu cinto.

${ }^{20}$ Nossa tradução: [...] A morte anterior do seu inimigo, o general Montonero Ángel Peñaloza, chamado "el Chaco", cometido de acordo com os cânones mais clássicos do Caos ou da Barbárie que agora se volta acusadora, como um bumerangue, da mão manchada por seus próprios homens.
} 
Na pesquisa desenvolvida por Imbert (1967), ele teve contato com uma série de cartas que foram enviadas a Domingo Faustino Sarmiento, entre 1866 e 1882, por Ida Wickersham. Imbert, como crítico literário e escritor, traduz estas cartas, escritas em inglês e francês, e reconta uma possível história de amor entre os dois. Essa versão de caráter mais histórico publicada por Imbert (1967) é reinterpretada por Lojo no conto em análise.

Ainda sobre a vida particular do protagonista histórico da narrativa, há inúmeras situações de relações afetivas que ficaram ocultas e que são consideradas tanto pelo professor Imbert quanto por María Rosa Lojo na estética literária de suas obras, segundo comenta Esteves (2011). De acordo com o pesquisador,

[...] em geral, as biografias de Sarmiento pouco tocam em sua vida amorosa. Abordar aspectos privados da vida deste homem público, que além de ter sido um dos principais intelectuais argentinos do séc. XIX, chegou a ser presidente da República, é uma tarefa que a história, de inspiração positivista, dá pouca importância. No entanto, a vida do ex-presidente argentino está povoada por relações amorosas que não seriam cultivadas pela moral burguesa da época. (ESTEVES, 2011, p. 49-50).

Em se tratando das relações que manteve com as mulheres que permearam sua vida, pode-se afirmar, de acordo com os autores mencionados, que a personagem foi um Sarmiento enamorado, pois manteve relacionamentos extraconjugais e com mulheres casadas e bem mais jovens, apesar de, segundo a História, não ser dotado da beleza estereotipada socialmente.

Dentre as mulheres de sua vida, conforme Esteves (2011), têm-se o conhecimento das histórias de María de Jesus del Canto, jovem chilena, com quem nunca se casou e com ela teve sua filha, Faustina, a qual reconheceu mais tarde. Ainda no Chile, teve um caso com uma mulher casada, Benita Martínez de Castro, que após ter ficado viúva, casou-se com Sarmiento, existe a possibilidade de o filho de Benita adotado por ele após o casamento, já ser fruto da relação que mantinham. Benita separou-se de Sarmiento quando descobriu sua relação com Aurelia Vélez Sarsfiel, uma jovem de 25 anos, também casada e que manteve sua relação com Sarmiento durante três décadas, apesar de nunca terem se casado.

Dessa maneira, a personagem Ida Wickersham - presente no conto "Amar a um hombre feo" - pode representar mais uma dessas relações de Sarmiento, cuja intensa vida amora dá o mote da escrita de Lojo no conto selecionado. 
Além das protagonistas Sarmiento e Ida, o leitor, ao longo da leitura se depara, também, com a presença da personagem Dr. Wickersham (médico) - marido de Ida na vida real, cuja visão é utilizada por Lojo como foco narrativo no final do conto.

O que se evidencia neste conto, é que a personagem de extração histórica mais relevante - Domingo Faustino Sarmiento - não sofre a desconstrução proposta pelo gênero do novo romance histórico latino-americano, a partir de recursos como a carnavalização, a paródia, o grotesco, as anacronias exacerbadas, o experimentalismo linguístico e formal, mas, sim, uma reconfiguração das inúmeras possibilidades e perspectivas da realidade, revelada pela narrativa híbrida de história e ficção em forma de conto que se aventura pela vida privada da personagem explorando seu lado mais humano.

Dessa maneira, essa escrita pode ser classificada como parte das produções literárias híbridas atuais, definidas por Fleck (2017), como sendo de mediação entre as escritas tradicionais e as críticas/desconstrucionistas. Essas, de acordo com o pesquisador, são comuns nos romances históricos contemporâneos de medicação, uma vez que a imagem do herói não é dessacralizada, mas vista e narrada sob a perspectiva do discurso de personagens que foram marginalizadas pela História oficial.

Nesse contexto, por meio da narrativa de uma aventura amorosa entre un hombre feo $y$ la beldad, a personagem Sarmiento é apresentada como um homem multifacetado que, apesar da posição de letrado e político, ainda assim, é frágil e solitário na visão da amada, mulher apaixonada, que ganha voz na escrita de Lojo, uma voz feminina que não foi considerada no discurso do colonizador e dos cânones literários por muito tempo. Tal constituição de visão e voz enunciativa é, conforme explicita Fleck (2017) recorrentes nas escritas híbridas mediativas que buscam mostrar o passado sob óticas "vistas de baixo".

Dessa forma, "contraditório, frágil e passível de engano como qualquer ser humano, [...], o Sarmiento que surge do conto difere da imagem infalível erigida pelos manuais escolares e do louco definido por seus inimigos políticos.” (ESTEVES, 2016, p. 77). Representa, assim, o que Mignolo (2007 apud COELHO, 2015, p. 13) chamou de mobilidade cultural, que considera a hibridez das Américas, a fim de apresentar uma nova forma de construir identidades e revelar o que foi oculto e invisibilizado.

É notória também a ruptura proposta pela escritora argentina quanto aos princípios impostos à cultura do seu país no século XIX, como o paradoxo civilização x barbárie, fato este que confere ao conto o seu aspecto insólito. 
A voz narrativa feminina, Ida Wickersham, relata sobre um amante desprovido do que o próprio Sarmiento tanto buscou: o ideal de civilização. Para a amada, o intelectual e político pelo qual ela se apaixona, apresenta-se em seus sonhos como um verdadeiro 'gaucho' e 'caudillo'. Por meio desse recurso de inversão, María Rosa altera o foco do relato e, segundo as palavras de Esteves (2011, p. 60), “[...] transforma o erudito intelectual, como ele próprio se considerava, num caudilho bárbaro, uma manifestação das forças naturais do deserto que ele tanto abominava.”.

María Rosa Lojo, por meio da memória literária, com êxito, consegue transpor a visão do colonizador, e possibilita outras leituras, outras perspectivas, passando a considerar 'o outro', que não aparece no discurso nacional.

\section{Referências}

AÍNSA, Fernando. La nueva novela histórica latinoamericana. Plural (México), n. 240, p.2885, 1991.

COELHO, Maria. Josele. Bucco. Mobilidades culturais na contista rio-platense de autoria feminina: tracejando as poéticas da distância em Josefina Plá e María Rosa Lojo. 2015. 200 f. Tese (Doutorado) - Curso de Letras, Universidade Federal do Rio Grande do Sul, Porto Alegra, 2015.

CRESPO BUITURÓN, Marcela G. Andar por los bordes. Entre la historia y la ficción: el exilio sin protagonistas de María Rosa Lojo. Lleida: Facultad de Letras de la Universidad de Lleida, 2008. (Tesis de Doctorado).

ESTEVES, Antonio. Roberto. Outras caras do poder: uma leitura de "Amar a un hombre feo", de María Rosa Lojo. In: Cultura e representação: ensaios. Assis: Triunfal Gráfica e Editora, 2011

ESTEVES, Antonio. Roberto. História e Memória em María Rosa Lojo (Tributo a Marilene Weinhardt). Revista Letras, Curitiba, n. 96, jun/dez 2016, p. 69-8787.

FLECK, Gilmei Francisco. A conquista do 'entre-lugar': a trajetória do romance histórico na América. Gragoatá, Niterói, v.2, p. 149-167, 2007.

FLECK, Gilmei Francisco. Gêneros híbridos da contemporaneidade: o romance histórico contemporâneo de mediação. In: RAPUCCI, Cleide A.; CARLOS, Ana Maria (Org.). Cultura e representação: ensaios. Assis: Triunfal Gráfica e Editora, 2011.p. 81-93.

FLECK, Gilmei Francisco. O PROCESSO DE LEITURA DO ROMANCE HISTÓRICO: confluências de perspectivas e discursos. In: $16^{\text {a }}$ JORNADA DE ESTUDOS 
LINGUÍSTICOS E LITERÁRIOS, 16. 2013, Marechal Cândido Rondon. Anais.... Marechal Cândido Rondon: Unioeste, 2013. p. 1 - 8.

FLECK, Gilmei Francisco. O romance contemporâneo de mediação: entre a tradição e o desconstrucionismo - releituras críticas da história pela ficção. Curitiba: CRV, 2017.

GUAL, Carlos García. Apología de la novela histórica y otros ensayos. Barcelona: Península, 2002.

GUIROY, P. Cuando la historia se convierte en vida. Disponível em: <http://elgranotro.com.ar/index.php/cuando-la-historia-se-convierte-en-vida/>. Acesso em: 26 jul. 2017.

HUTCHEON, Linda. Poética do pós-modernismo. Trad. de Ricardo Cruz. Rio de Janeiro: Imago, 1991.

LOJO, María Rosa. Amores Insólitos de nuestra historia. Buenos Aires: Alfaguara, 2001.

LUKÁCS, Gyorgy. A teoria do romance: um ensaio histórico-filosófico sobre as formas da grande épica. Tradução José Marcos Mariani de Macedo. São Paulo: Editora 34 Ltda., 2000.

MENTON, Seymour. La nueva novela histórica da la América Latina 1979-1992. México: Fondo de Cultura Económica, 1993.

PAPESCHI, Muryel da Silva. Juan Facundo Quiroga: um homem, vários personagens. 2014. 121 f. Dissertação (Mestrado) - Curso de Letras, Universidade Estadual Paulista, Assis, 2014.

RODRÍGUEZ, A. Márquez. Historia y ficción en la novela venezoelana. 2.ed. Caracas: Talleres de Anauco Ediciones, C. A., 1996.

SANTIAGO, Silviano. Uma literatura nos trópicos. 2.ed. Rio de Janeiro: Rocco, 2000.

WEINHARDT, Marilene. Ficção e história: retomada de antigo diálogo. Revista de Letras. Curitiba: Editora UFPR, no. 58. jul.dez. 2002, p. 105-120.

Recebido em 20 de janeiro de 2020. Aceito em 28 de abril de 2020. 